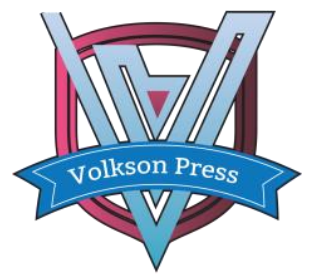

Contents List available at VOLKSON PRESS

Economics \& Management Innovations(EMI)

DOI : http://doi.org/10.26480/icemi.01.2017.254.257

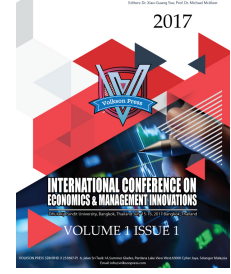

\title{
Quality of working life - macroergonomics point of view
}

\author{
Aleksandra Jasiak ${ }^{1, *}$ \\ ${ }^{1}$ Poznan University of Technology, Poland \\ "e-mail aleksandra.jasiak@put.poznan.pl \\ This is an open access article distributed under the Creative Commons Attribution License, which permits unrestricted use, distribution, and reproduction in any \\ medium, provided the original work is properly cited.
}

\section{ARTICLE DETAILS}

\section{Article History:}

Received 02 october 2017

Accepted 06 october 2017

Available online 11 october 2017

Keywords:

quality of working life, ergonomics,

macroergonomics, participatory ergonomics

\section{ABSTRACT}

Quality of working life is one of the aspects of social dimension of sustainable development. It has been field of interest of managers for many years, since it is considered both an element of competitive edge of a company and of research conducted by scientists searching for factors influencing its level. Continuously, for many years, macroergonimics (third generation of ergonomics) has been supporting practitioners and academics in meeting their goals. The paper presents the term of macroergonomics and its range, as well as identification of factors influencing quality of working life based on the literature on the subject. Moreover, it introduces contribution of participatory ergonomics to improving satisfaction of employees and improving quality of working life.

\section{Introduction}

The analysis and design of jobs and work organization have been continual themes in the organization and management science literature. Both higher productivity and better working conditions have been sought through the analysis and design of jobs and organizations [1, 2]. Also the quality of working life has received much attention. Traditionally this attention has originated from perceiving humans as a basic asset: the productive engine of a modern work organization. The goal of the paper is to present the role of macro-ergonomics in developing employee-friendly work environment, and consequently, contributing to increasing quality of working life.

\section{Macroergonomics approach}

According to [3] ergonomics is the theoretical and fundamental understanding of the human behavior and performance, purposely interacting in sociotechnical systems, and the application of understanding of how to design interactions in the context of real settings. From this point of view, ergonomics can be considered a multidisciplinary field such as the psychology, anthropometry, anthropotechnology, applied physiology, environmental medicine, engineering, statistics, operations research and industrial design. The discipline contributes to the design and evaluation of organisations, tasks, jobs and equipment, environments, products and systems. It focuses on the inherent characteristics, needs, abilities and limitations of people and the development of sustainable and safe working cultures [4]. Human factors, can simultaneously affect a company's safety culture, and at the same time being a factor influencing job satisfaction. Ergonomics and human factor has always been important to manufacturing, particularly from the industrial revolution when people and machinery were forced together in large-scale mass-production factory environments and socio-technical problems began to emerge as a result. Although manufacturing engineers and managers have traditionally focused on developing technical systems to replace people, there is now an increasing recognition that even in highly advanced and automated production processes people are still essential for various roles.

The third generation of ergonomics is macroergonomics (Fig.1). It is defined as "a top-down sociotechnical systems approach to the design of work systems, and the carry-through of overall work system design to the design of the human-job, human-machine, and human-software interfaces" [5].

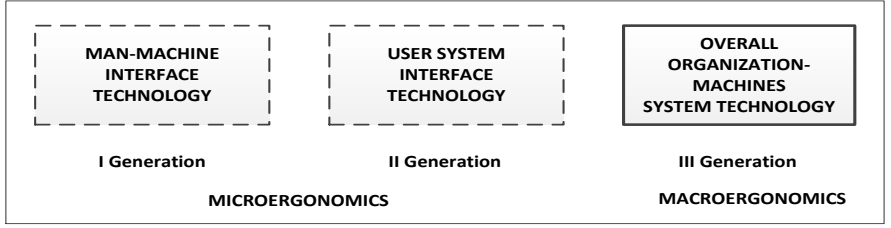

Figure 1 Ergonomics evolution [6]

Macroergonomics is concerned with the optimization of sociotechnical systems [7]. By focusing on the social and technical, and aiming for their systemic optimization, socio-technical systems (STS) was the first approach which succeeded in making the workplace more humane, and more productive, at the same time (Fig. 2). STS seeks to create jobs that satisfy employees' psychological needs and thus pave way for employee well-being and organizational productivity [8]. Carayon et al [9] suggest that sociotechnical systems are a type of complex adaptive system, and that analysis from that perspective could significantly enhance our understanding of how sociotechnical systems function and how they might be made to function better.

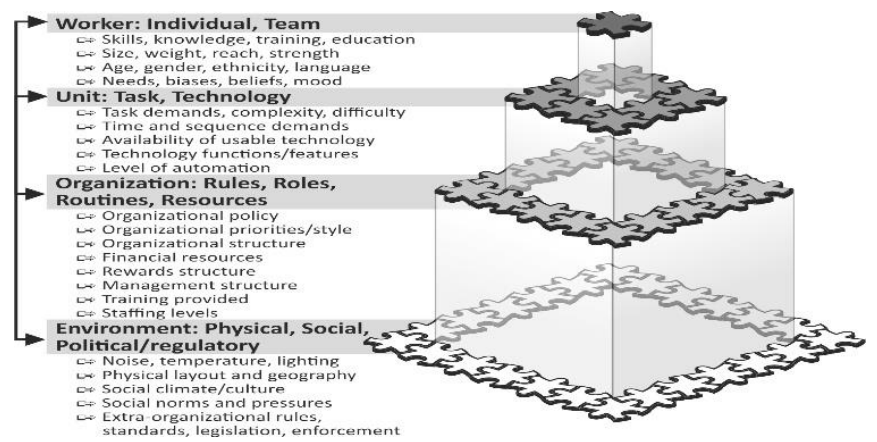

Figure 2. Socio - technical system

Macroergonomics is concerned with the optimization of sociotechnical systems, including their organizational structures, policies and processes. Our civilization generates many problems related to human factor that cannot be solved by one branch of expertise, mostly because each branch approaches the problem in a fragmentary way $[10,11]$. Macroergonomics tries to deal with this challenge, as it connects organization and 
management of work with axiology, sociology, psychology, pedagogy, technical sciences and economics. This approach can produce benefits for manufacturing systems, from process optimization and reduction of occupational risks to the notable improvement of quality of working life.

\section{Quality of working life}

The history of term QWL dates back to the last century, nearly about 1960s. Complete historical overview of QWL is described by [12]. During this period many definitions and sets of indicators or characteristics were published. Quality of working (QWL) life has been defined by many researchers in a variety of ways $[13,14,15,16]$. QWL can be defined as an extent to which an employee is satisfied with personal and working needs through participating in the workplace while achieving the goals of the organization. Quality of work life expresses a philosophy, a set of principles that highlight the fact that people represent the most important resource in an organization and deserve to be treated with dignity and respect. Some authors define the quality of work life as the physical, mental and emotional well-being of employees at work.

It is gaining more attention due to many researchers have considered different variables which are related to job satisfaction, job security, wages etc. However there are many other critical factors which contribute to QWL which includes physical, physiological and social aspects. The important issue in defining QWL is answering the question: what aspects of life in their working place are important for organization members? According to author's opinion based on the review of the literature $[17,18$, $19,20]$ aspects of QWL could be categorized into six groups including:

(1) organization culture (e.g. involvement in decision making, cooperation from other department, uniformity of wage policies, gender discrimination, communication, comments and suggestion,);

(2) relation and cooperation (e.g. relationship with colleagues, work demand stress, relationship with immediate superior, communication system in the firm, communication channel);

(3) work environment (e.g. motivating environment, working condition, support for self-development, information's related to work, training and development);

(4) facilities (e.g. social security, safety measures, welfare activity);

(5) autonomy of work (e.g. ability to work, flexible time, job stress, additional responsibility, balanced objectives and facilities);

(6) job satisfaction and job security (e.g. comfortableness in work, job security, productivity, trade union activity, fair job rotation).

The general goal of QWL program is to satisfy the full range of employee needs. The management of an organization has a responsibility to take all steps necessary to improve QWL of all workers. The management has to ask itself the following question: How will it organize the work, the communications patterns, the decision making, the norms and values, the ground rules, so that people's individuals needs for self-worth, achievement, satisfaction and so on, are significantly met at the workplace? Techniques to improve quality of work life include job redesign, career development, flexible work schedules, job security and the like. The tools supporting improvement of quality of working life are delivered by, among others, ergonomics, and especially one of its latest interpretations, that is macro ergonomics. If any organization properly adopts these techniques, the QWL will certainly be improved to the desired levels.

\section{Macro ergonomics approach for quality of working life improvements}

The scope of macroergonomics is large: construction [21], healthcare [22], and manufacturing [23, 24, 25]. Participatory ergonomics is a primary methodology of macroergonomics which involves employees at all organizational levels during the design process [26]. Wenger [27] refers to participation as 'a process of taking part and also to the relations with others that reflect this process'. It is a complex process that includes, for example, doing, talking, thinking, feeling and belonging. Participation involves action, e.g., talking with someone, and connection, e.g., feeling that one takes part. Participation as a method of involving employees in actions supporting company is an element of all the contemporary management concepts, however its goal differs on account of the approach. In lean management (LM) employees' participation strives for involving employees in actions towards increased productivity achieved thanks to identification of actions that are not adding value from customers perspective. LM approach presents the human element as a fundamental factor for continuous improvement sustainability [28]. On the other hand in TQM participation is a team-oriented method striving for solutions improving clients' satisfaction. And though the term client in quality management refers to both internal (employees) and external clients, the actions toward satisfaction improvement are focused mainly on the latter Generally, for both (LM and TQM) increased satisfaction of employees can be the added value of efforts taken, however it more a side effect than a goal set.

Macroergonomics is the study of work systems that focuses on the achievement of a fully-harmonized work system at both the macroergonomic and microergonomic levels (Fig. 3)

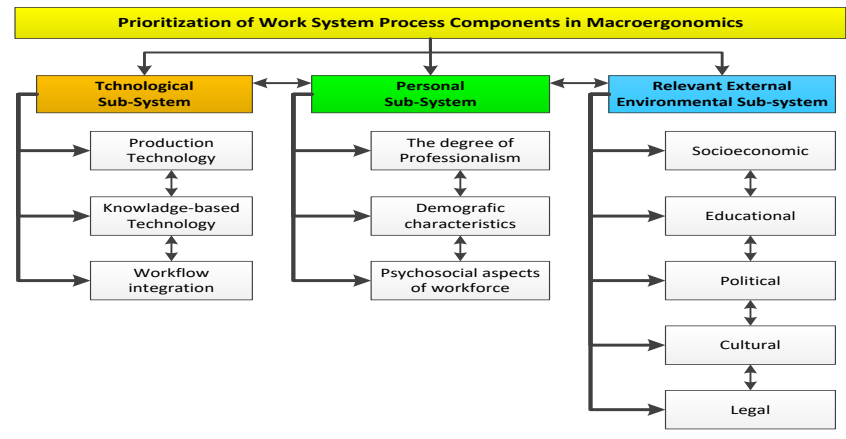

Figure 3. Hierarchical structure of sociotechnical system components of work system process [29]

Participatory ergonomics is an important factor promoting initiatives of employees and high efficiency in implementing actions improving work methods, work conditions and risk management. The literature presents numerous definitions of participatory ergonomics. The common characteristic is that in a change process, attention is paid explicitly to the role of participants. According to $[30,31,32,33,34,35,35,37]$ in participatory ergonomic project, ergonomists and employees play an essentials role in the improvement process ('ergonomists (or other experts working on work improvement) are involved, because they add a new realistic vision and employees are involved because of changes in their work-and they may know best what and how to change').

Work design can help to enhance the basic relationship between people and their jobs [38]. The basic foundation of this relationship is that nature of work itself is a powerful influence on worker motivation and job satisfaction. People who are happy with their jobs are highly intrinsically motivated. Management can take and adopt some steps to makes the job more interesting for the worker. They can together with workers redesign the job and to make it more interesting and motivational for the worker Job redesign involves revising job descriptions and changing the nature of work so as to induce higher level of motivation among workers. The actions influence mostly organizational safety culture and work culture, relations with colleagues and good communication, as well as understanding the needs and expectations of staff and building the interdependence culture.

\section{Conclusions}

Quality of Work Life reflects the relationship between personnel and work environment that encourages learning and self-development, which will leads to meet the satisfaction of employees.

New paradigm shifts resulting in new forms of organization (e.g. industry 4.0), new management paradigms (e.g. corporate sustainability, sustainable supply chain [39]) and new form of social challenge. The next significant step in improving working environment and workers job satisfaction lies in looking beyond traditional approaches and exploring the potential of sociotechnical systems to address the fundamental challenges associated with new technologies, emerging industries and the ever-changing workforce [40, 41].

\section{References}

[1] M. Jasiulewicz-Kaczmarek, P. Drożyner, Preventive and ProActive Ergonomics Influence on Maintenance Excellence Level, [in.] M.M. Robertson (Ed.): Ergonomics and Health Aspects, HCII 2011, LNCS 6779, pp. 49-58 (C) Springer-Verlag Berlin Heidelberg, 2011

[2] A. Burduk, Assessment of risk in a production system with the use of the FMEA analysis and linguistic variables, in: Emilio Corchado 
(eds.) Hybrid Artificial Intelligent Systems Proceedings of the HAIS2012 Conference, Springer ,Series: Lecture Notes in Computer Science. Lecture Notes in Artificial Intelligence, Vol. 7209, 2012, pp. 250-258

[3] J. R. Wilson, Fundamentals of systems ergonomics / human factors. Applied Ergonomics, 45, 2013, pp. 5-13.

[4] M. Butlewski, M. Jasiulewicz-Kaczmarek, A. Misztal, M. Sławińska, Design methods of reducing human error in practice, in: Nowakowski, T; Mlynczak, M; Jodejko-Pietruczuk, A; et al. Safety and Reliability: Methodology and Applications - Proceedings of the European Safety and Reliability Conference, ESREL 2014 Location: Wroclaw, POLAND Date: SEP 14-18, 2014 Taylor \& Francis Group, London, 2015, pp. 1101-1106,

[5] H.W. Hendrick, B.M. Kleiner, Macroergonomics: Theory, Methods and Applications. Mahwah, New Jersey: Lawrence Erlbaum, Associates, Publishers, 412, 2002

[6] L. Pacholski, A. Jasiak, Macroergonomics (in polish), Wydawnictwo Politechniki Poznańskiej, Poznan 2011

[7] A. Jasiak, Macroergonomics in the design of work systems and quality of life (in polish), Wydawnictwo Politechniki Poznańskiej, Poznan 2015

[8] M. Jasiulewicz-Kaczmarek, Socio-technical integrity in maintenance activities, in: Vink P. (eds.): Advances in Social and Organizational Factors, CRC Press 2012, pp. 582-592

[9] P. Carayon, P. Hancock, N. Leveson, I.Noy, L. Sznelwar, G. van Hootegem, Advancing a Sociotechnical Systems Approach to Workplace Safety - Developing the Conceptual Framework. Ergonomics 58.4, 2015, pp. 548-564

[10] A. Misztal, M. Butlewski, A. Jasiak M., Janik S., 2014, The human role in a progressive trend of foundry automation, METALURGIJA 54 (2015) 2, pp. 429-432

[11] A. Jasiak, The Fourth Face of Macroergonomics, Zeszyty naukowe PP, 71, pp. $137 \quad-\quad 150,2016$ http://zeszyty.fem.put.poznan.pl/numery/ZN OiZ PP 71 13.pdf

[12] J.P. Martel, G. Dupuis, Quality of work life: Theoretical and methological problems, and presentation of new Model and measuring instrument. Social indicator Research. 77, 2006, pp 333-368

[13] D.A. Nadler, E.E. Lawler, Quality of Work Life: Perceptions and Directions Organizational Dynamics. 11(3), 1983

[14] M. J. D Sirgy, P. Efraty, P.SIEGEL, L. Dong-Jing, A new measure of quality of work life (QWL) based on satisfaction and spillover theories. Social Indicator Research 55, ,2001, pp. 241-302

[15] L.S. Beh, R. E. Che, Linking QWL and Job Performance: Implications for Organizations, Performance improvement; July 2007; 46, 6; pp. 30-34.

[16] Kanten, S., \& Sadullah, O. An empirical research on relationship quality of work life and work engagement. Procedia-Social and Behavioral Sciences 62, 2012, pp. 360-366.

[17] D. M. L. Reddy, P, D. M. Reddy, Comparative analysis of quality of work life among public and private sector bank employees. International Journal of Organizational Behaviour \& Management Perspectives, 2(4), 2014, pp. 641- 648.

[18] T S. Nanjundeswaraswamy D R Swamy, Quality of work life of employees in private technical institutions, International Journal for Quality Research Vol. 7(3), 2013, pp 431-441

[19] R. C., Rose, L.Beh, J. Uli, K. Idris, Quality of work life: implications of career dimensions. Journal of Social Sciences, 2(2), 2006, pp. 61.

[20] R. Rusu, The influence of quality of work life on work Performance, International Conference KNOWLEDGE -BASED ORGANIZATION Vol. XXII No 2, 2016, pp. 490 - 495

[21] S. Ghosh, D. E. Dickerson, Modified Interaction Process Analysis as a Macroergonomic Method of Analyzing Communication Patterns in
Construction. IIE Transactions on Occupational Ergonomics and Human Factors. 3 (1), 2015, pp. 45-57

[22] M. Fray, P. Waterson, C. Munro. Macro and micro ergonomic outcomes in healthcare: Unravelling the relationship between patient handling performance and safety climate. IIE Transactions on Occupational Ergonomics and Human Factors. 3 (1), 2015, pp. 58 - 71

[23] N. Larson, H. Wick, S. Hallbeck, P. Vink. Corporate Ergonomics Programs: Identifying value through a company award process. IIE Transactions on Occupational Ergonomics and Human Factors. 3 (1), 2015, pp. $9-23$

[24] Tompa E, Dolinschi R, Natale J. Economic evaluation of a participatory ergonomics intervention in a textile plant. Applied Ergonommics 44(3), 2013, pp. 480-487.

[25] Realyvásqueza, A.A. Maldonado-Macíasa, J.L. García-Alcaraza, J Blanco-Fernándezb, Effects of organizational macroergonomic compatibility elements over manufacturing systems' performance Procedia Manufacturing 3, 2015, pp. 5715 - 5722

[26] A.S., Imada, K. Noro, M. Nagamachi, Participatory ergonomics: Methods for improving individual and organizational effectiveness. In 0 Brown, Jr., \& Hendrick (Eds.), Human factors in organizational design and management II, 1986, pp. 403-406.

[27] E. Wenger, Communities of practice: Learning, meaning, and identity: Cambridge University Press, Cambridge 1998

[28] G.L. Tortorella, L.G.L. Vergara, E.P. Ferreira, Lean manufacturing implementation: an assessment method with regards to socio-technical and ergonomics practices adoption, Int J Adv Manuf Technol 89, 2017, pp. $3407-3418$

[29] G. Koyuncu, E. Kurt, Y.C. Erensal Work System Design in Macroergonomics: A Case Study Related to Prioritization of Major Sociotechnical System Components by Using the Fuzzy Analytic Network Process, Human Factors and Ergonomics in Manufacturing \& Service Industries 21 (1), 2011, pp. 89-103

[30] P. Vink, E Koningsveld, J.F. Molenbroek, Positive outcomes of participatory ergonomics. In term sof greater komfort and higher productivity, Applied Ergonomics, Vol. 4, 2006, pp. 537-546.

[31] S. Hignett, J.R. Wilson, W. Morris, Finding ergonomic solutions-participatory approaches. Occup. Med. 55, 2005, pp. 200 - 207

[32] D.M. Zalk, Grassroots ergonomics: initiating an ergonomics program utilizing participatory techniques. The Annals of Occupational Hygiene 45, 2001, pp. 283 - 289

[33] 0. Broberg, V. Andersen, R. Seim, Participatory ergonomics in design processes: The role of boundary objects , Applied Ergonomics Volume 42, Issue 3, 2011, pp. 464-472

[34] S. Nobrega, L. Kernan, B. Plaku-Alakbarova, M. Robertson, N. Warren, R. Henning, Field tests of a participatory ergonomics toolkit for Total Worker Health. Applied Ergonomics Volume 60, April 2017, pp. 366379

[35] M.M. Robertson, R.A. Henning, N. Warren, et al., Participatory design of integrated safety and health interventions in the workplace: a case study using the Intervention Design and Analysis Scorecard (IDEAS) Tool. Int. J. Hum. Factors Ergon. 3, 2015, pp. 303-326.

[36] K. Nielsen, R. Randall, The importance of employee participation and perceptions of changes in procedures in a team working intervention. Work Stress 26, 2012, pp. 91-111.

[37] D. Van Eerd, T. King, K. Keown, et al., Dissemination and use of a participatory ergonomics guide for workplaces. Ergonomics 2016, 59, pp. 851-858

[38] Habibi E, Zare M, Amini N.R, Pourabdian S, Rismanchian M. Macroergonomic conditions and job satisfaction among employees of an industry. International Journal of Environmental Health Engineering 2012;1:34

[39] Grzybowska K., Kovács G., Sustainable supply chain - supporting tools, Preprints of the Federated Conference on Computer Science and Information Systems, September 7-10, 2014. Warsaw, Poland, M. Ganzha, 
L. Maciaszek, M. Paprzycki (eds.), pp. 1351-1359, DOI: $10.15439 / 2014 \mathrm{~F} 75$

[40] P. Carayon, T. B. Wetterneck, A. J. Rivera-Rodriguez, A. S. Hundt, P. Hoonakker, R. Holden, and A. P. GursesHuman Factors Systems Approach to Healthcare Quality and Patient Safety. Applied Ergonomics 45 (1), 2014, pp. 14-25.
[41] S. W. A. Dekker, P. A. Hancock, P. Wilkin. Ergonomics and Sustainability: Towards an Embrace of Complexity and Emergence. $\begin{array}{lllll}\text { Ergonomics } & 56 & \text { (3) 2013, pp. 357-364 }\end{array}$ 